\title{
Wir leben nicht in der besten der Welten, aber gewiss auch nicht in der schlechtesten
}

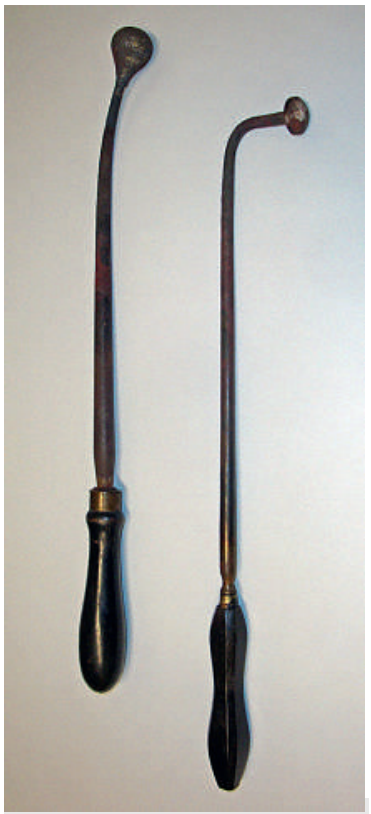

Heute zur Therapie einer Hüftluxation nicht mehr das Instrument der Wahl: Brenneisen, um 1800 (Medizinhistorisches Institut und Museum der Universität Zürich).

\footnotetext{
* Dr. med. Werner Bauer, Facharzt für Innere Medizin FMH, Mitglied der Redaktion, ist praktizierender Internist, Präsident des Schweizerischen Instituts für ärztliche Weiter- und Fortbildung SIWF und Past-Präsident der European Federation of Internal Medicine EFIM.
}

Beim Durchstöbern der Buchauslage im Zürcher Medizinhistorischen Museum bin ich auf Berichte aus vergangenen Zeiten gestossen, die mich nachdenklich gestimmt haben.

In einer Broschüre von Robert Henri von Muralt, «Ärzte aus dem Zürcher Patriziat», liest man:

«Den 10. März 1825 wurde ein Kind von 14 Jahren mit einer luxatio spontanes des linken Oberschenkels in den Spital aufgenommen, die luxatio ging nach oben, denn das Bein war beträchtlich kürzer als das andere, und da man schon mehrere Spuren von früher aufgelegten Blasenpflastern bemerkte, so fasste man den Entschluss, die Glüheisen anzuwenden.»

Ich erspare den Lesern die genaue Beschreibung der «4-5 Zoll langen Striche in der Gegend des Trochanters und der Pfanne» und bin froh, dass wir heute anästhetisch und analgetisch gutversorgt mit einer erfolgreichen Reposition rechnen dürfen.

Im gleichen Buch an anderer Stelle liest man:

«Auf einem Ausritt nach Münden stiess Muralt auf ein havariertes Fuhrwerk, von dem ein Zugpferd zuvor durchgebrannt war. Etwa tausend Schritte davon entfernt fand er den Knecht mit gebrochenem Bein auf der Strasse liegen.» Dass die herumstehenden Passanten nicht wussten, wie sie dem Verunfallten helfen konnten, kann man ihnen wohl nicht verargen. Als er aber um improvisiertes Fixations- und Polstermaterial bat, war die Reaktion negativ: «Ich forderte nämlich Nas- oder Halstücher, allein, obgleich der Herr sagte: «Es wird ja alles bezahlt`, hatten sie doch weder Zutrauen zu seinen Äusserungen noch genug Mitleid für den leidenden Knecht, dass sie genug Tücher hergegeben hätten. Freylich war das Beypiel des Herren keineswegs geeignet, die Bauern zur Hilfe anzuspornen, denn er schimpfte und gab selber weder Nastuch noch Halstuch her, noch leistete er überhaupt tätliche Hilfe, dann würdigte er mich kaum eines Dankes.»

Heute ist für uns eine schnelle, kompetente Notfallversorgung ohne Ansehen des Standes eines Unfallopfers selbstverständlich. In den allermeisten Fällen ist die professionelle Hilfe auch gewährleistet, nur mit dem Beitrag allfälliger Zuschauer ist es auch in unseren Tagen noch so eine Sache.

In einer Dissertation (Sebastian Brändli: «Die Retter der leidenden Menschheit», 1990) finden sich folgende aufschlussreiche Passagen zur «Ressourcenallokation» vor gut 200 Jahren:

«Im Arzneibuch des jungen Grafferus (1754) gab es beispielsweise zweierlei Arten von Bruchsalben: eine erste <edle und sehr köstlich Bruch Salb vor reiche Leut, eine zweite sgemein Bruch Salb für arme Leut».

Die Zweiklassenmedizin war offensichtlich $\mathrm{zu}$ jenen Zeiten der Normalfall und nicht Gegenstand von Diskussionen wie heute. Inwieweit die «köstlich Bruch Salb» eine Hernie wirksamer beeinflusste als die «gemein Bruch Salb», ist eine andere Frage. Evidence based medicine war wohl noch nicht Bestandteil des Lehrplans im «collegium anatomicum».

Immerhin gab es gegen Ende des 18. Jahrhunderts zwar keine Krankenkassen, aber obrigkeitliche Tarifordnungen, die auf die wirtschaftliche Leistungsfähigkeit Rücksicht nahmen und Pauschalvergütungen vorsahen:

«Bei Entbindungen sogenannter Rüdenfrauen (Frau eines vermutlich wohlhabenden Mitglieds der Gesellschaft zur Constaffel) erhielt die Hebamme 10 Schilling, bei einer Schneggenfrau (Frau eines Gesellschafters zur Schneggen) 5 Schilling, von allen anderen Frauen 3 bis 4 Schilling, beim ersten Kind allerdings 5 Schilling.»

Auch Ärzte mit Jahrespauschalen zu entschädigen, war im achtzehnten Jahrhundert offenbar ein gängiger Modus: «Eine Besonderheit des Arzthonorars, die generell im Handwerk zu finden war, soll noch erwähnt werden: der Jahreslohn.» Überliefert ist der Fall eines Konrad Toggenburger von Marthalen: «Nach etlichen Jahren seines Wirkens schon, empfing er einen Ruf als Stadtarzt nach Lenzburg (...). Als nun aber diese seine Absicht in der Umgegend bekannt wurde, verursachte die Möglichkeit, einen geschickten und sorgfältigen Arzt zu verlieren, grosses Bedenken und schnell fanden sich die benachbarten Schlösser und Honoratioren zusammen, setzten ihm einen Jahresgehalt fest und vermochten auf diese Weise zur Freude der ganzen Gegend ihn in ihrer Mitte festzuhalten.»

Wir mögen heute neue, vielfältige und schwer lösbare Probleme im Gesundheitswesen haben. Wenn aber wieder einmal ein Journalist oder ein Politiker verkündet, so schwierige und so schlechte Zeiten wie heute hätte es überhaupt noch nie gegeben, müsste man ihm die Pflichtlektüre alter Berichte verordnen. Dank Linsenersatz ist ihm diese Lektüre heute auch bei fortgeschrittener Katarakt noch möglich, in den gelegentlich so gelobten alten Zeiten hätte er auf den vorbeiziehenden Starstecher warten müssen ...

Werner Bauer* 